\title{
Spending on locums has fallen $44 \%$ since introduction of wage cap
}

\author{
Tom Moberly UK editor
}

The BMJ

Spending on locums by NHS trusts has fallen by $44 \%$ since the introduction of wage caps and other measures aimed at controlling the rising cost of agency staff.

The service sought to introduce measures to control spending on locums after paying $£ 3 \mathrm{bn}$ ( $€ 3.4 \mathrm{bn} ; \$ 3.9 \mathrm{bn}$ ) for agency staff in 2014-15. In November 2015 a cap on the hourly rate that trusts could pay locums was introduced. Trusts can hire staff above the capped rate when there is a legitimate patient safety requirement.

Data from NHS Improvement show that $£ 331 \mathrm{~m}$ was spent on agency staff in July 2015 . This fell to $£ 193 \mathrm{~m}$ a month by September 2018, the latest period for which figures are available.

As a proportion of the overall NHS wage bill, the amount spent on locums has fallen by $50 \%$ since April 2015. Agency staff accounted for $7.2 \%$ of NHS spending on staff in April 2015 and $8.2 \%$ in July 2015. By September 2018, this had fallen to 4.1\%.
The proportion of NHS spending on doctors' wages that is spent on agency workers is higher than that for other staff groups. The proportion of NHS spending on medical staff that is spent on agency workers was $7.0 \%$ in September 2018.

Liaison, a company that manages staff payment systems, gathered data on the pay and agency commission rates paid to over 5500 bank and agency doctors by 55 NHS trusts between July and September 2018. The company found that, over this period, the average locum pay for all doctors was $£ 74.74$ per hour. The average for consultants was $£ 101.21$; for higher trainees it was $£ 70.68$; and for staff grade doctors it was $£ 68.07$.

Data from 55 NHS trusts provided by Liaison.

Published by the BMJ Publishing Group Limited. For permission to use (where not already granted under a licence) please go to http://group.bmj.com/group/rights-licensing/ permissions 


\section{Figures}




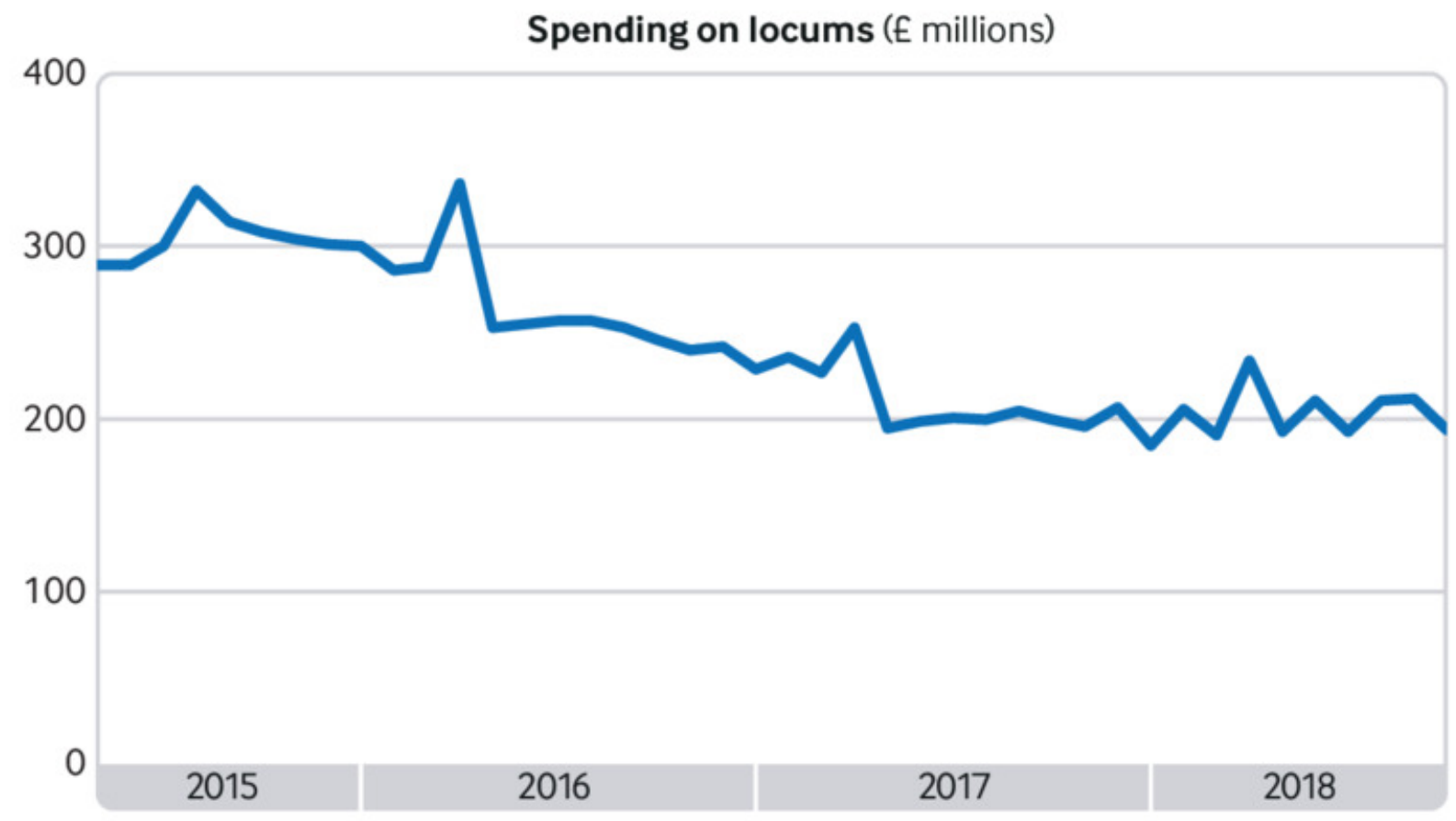

Spending on locums

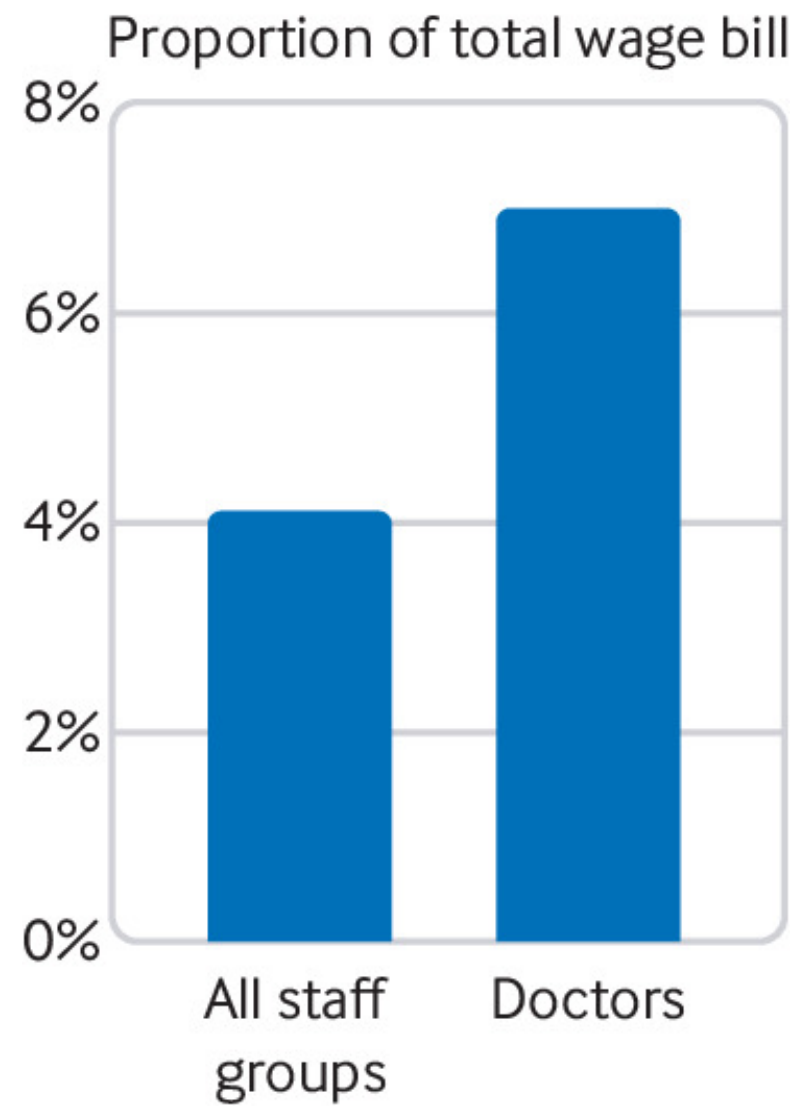




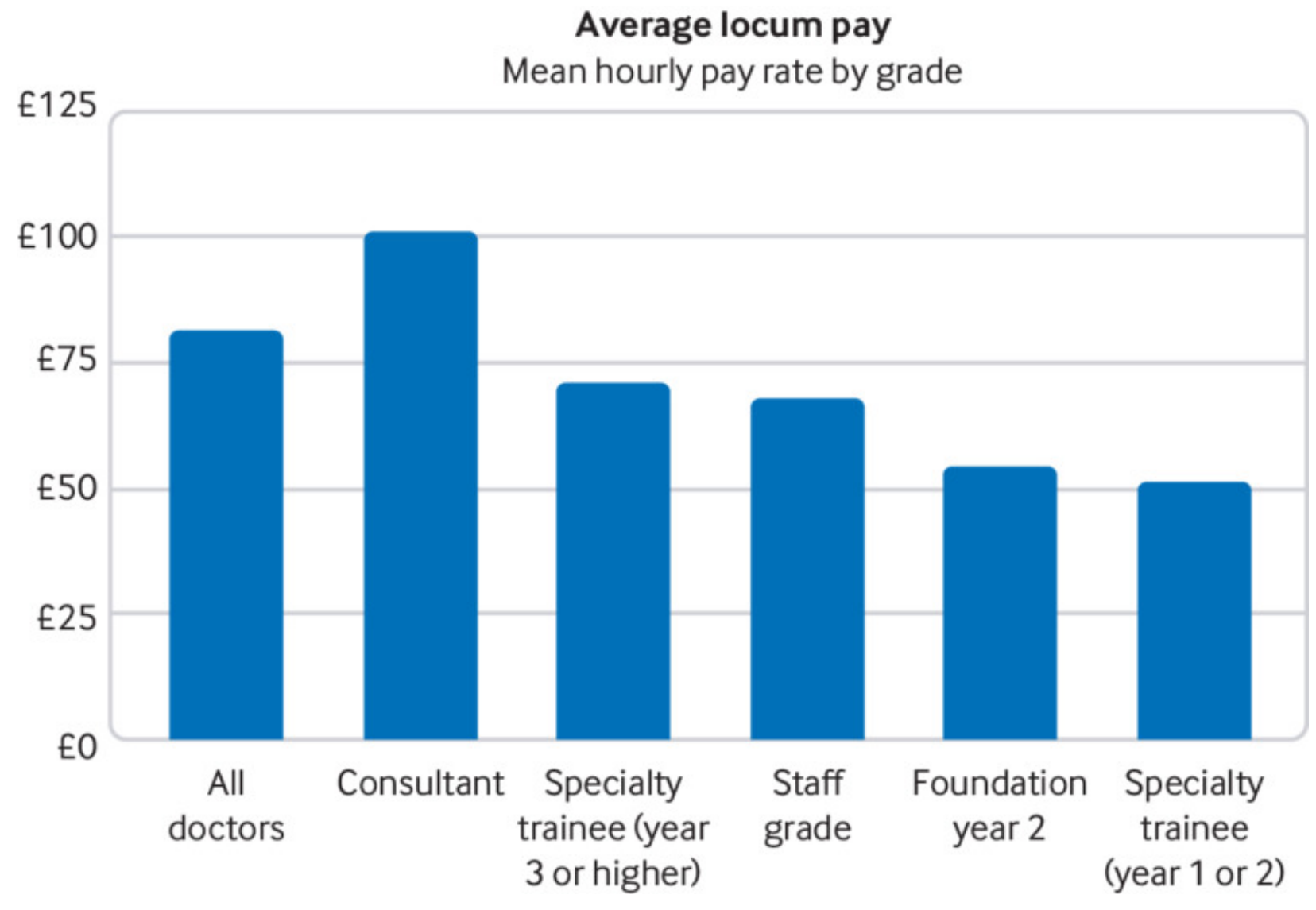

